\title{
MISSING WHITMAN NOTEBOOKS RETURNED TO LIBRARY OF CONGRESS
}

\author{
Alice L. Birney
}

\section{The Call}

ON JANUARY 25, 1995, I received a message from a Selby Kiffer of Sotheby's Book and Manuscript department in New York City. He wanted to "track down the location" of a Whitman notebook first published in Emory Holloway's 1921 Uncollected Poetry and Prose of Whitman (pp. 63-76). Kiffer asked if Holloway's citation on this notebook"made available by Harned"-meant that the notebook was a permanent gift or a temporary deposit in the Library of Congress. He also inquired if this notebook was still in the Library. Although I wondered how Kiffer had reached my office, I later learned that he had already done extensive research in the New York Public Library in order to find that particular citation on the notebook. I remember immediately wondering whether he had found one of our long lost Whitman notebooks.

After checking the Holloway text, I found that it matched the description of Notebook No. 1, the so-called "earliest known" and "most important" Whitman notebook, described in the Library of Congress 1954 publication, Ten Notebooks and A Cardboard Butterfly Missing from the Walt Whitman Papers. I telephoned Mr. Kiffer to claim the notebook after determining that his "research" on the subject was not for himself but for Sotheby's. I said that the notebook should be returned to the Library of Congress as it was clearly government property. He requested a copy of the 1954 publication, which I said had been prepared on the advice of the Federal Bureau of Investigation, and asked me to repeat its whole title. Little did I know that my mention of the "cardboard butterfly" named in our publication was key to their decision that government property had been offered to Sotheby's. I promised to mail the booklet, as it was not suited for Fax transmission. Later that day Kiffer left me another message, requesting that five copies of the 1954 pamphlet be sent via overnight mail. He said, "It seems plausible and possible that the inquiry I mentioned might match up with some of that material, and of course we are eager to see if that's the case as soon as we can." I left a message that the booklets would arrive at 10:30 a.m. 
January 26 via Federal Express. I said, also, "If an anonymous party wishes to leave the notebook with Sotheby's, I would come to New York and get it in person."

On Friday, January 27, David Redden, Sr., Vice President of Sotheby's, telephoned me to say that he was holding for us not one but four notebooks and the butterfly which they had positively identified as items numbered 1, 2, 5, 7, and 11 in the 1954 Library of Congress pamphlet. Missing since at least 1944, these unique items at last had been found. Redden told me that a New York lawyer settling the estate of his father, who had died two years before, had found the Whitman items in his father's papers and had inquired at Sotheby's about selling them. The found notebooks correspond with the following L.C. numbers in Walt Whitman, A Catalog Based Upon the Collections of the Library of Congress (Washington, 1955): (A) \#80 [Notebook. 1847]; (B) \#86 [Notebook. Before 1855]; (C) \#94 [Notebook. 1862-63]; (D) \#101 [Washington hospital notebook. ca. 1863-64]; (E) \#220. Cardboard butterfly. These were among a group of 24 Whitman notebooks deposited with the Library in 1918 by Thomas B. Harned. Redden had already telephoned the Librarian of Congress, Dr. James H. Billington, who was reported to have said, "This is an event of national importance."

During the next week I researched Manuscript Division case files, Library of Congress Archives, and Exchange and Gift files in order to supply to Sotheby's information for the "finder," who reportedly was very surprised when informed about the legal ownership of the notebooks. He did not contest the Library's claim to the materials, but, needing to satisfy family inquiries about relinquishing the manuscript notebooks, requested evidence of how the items came to the Library, proof that they were never officially deaccessioned, and information on efforts made to locate them. He also asked to remain anonymous, and Sotheby's, as well as the Library, have honored that request, though the FBI subsequently interviewed him in the course of their standard investigation on the return of government property.

On February 2, I hand-carried a letter summarizing my findings, together with a stack of supporting documents, to the Library's legal counsel for approval before sending it to Sotheby's. As required, he reported the development to the Library's protective services department, and a Library detective visited me the next day about the case. $\mathrm{He}$, in turn, was required to call in the Federal Bureau of Investigation to determine if their old Library/Whitman case file was still open, to report the results so far, and to get their advice on procedures for the return of possibly stolen property. He also recommended using the television show Unsolved Mysteries to locate the remaining notebooks. Later consultation with the F.B.I. has caused the Library to postpone this possible course of action until their follow-up inquiry is completed. 


\section{The Return}

Six people were involved in the actual return of the found Harned / Whitman materials from Sotheby's to the Library on February 24, 1995, during a twelve-hour transaction: three F.B.I. agents, two conservators, and one literary manuscript specialist. I left home at 6:15 a.m., parked my car atop Union Station, and boarded the 7:00 a.m. Metroliner. Two of the others had gone to New York the day before, so I used the travel time to compare the published parts of the found notebooks with copies of our partial photostats made before their World War II disappearance. I arrived at Sotheby's by taxi at 10:30 in a wild hail of sleety snow. Already there were Special Agent of the F.B.I. Pat Gibbons, who controls the case from the D.C. office; two New York agents; and Terry Wallis, Library of Congress rare book conservator, ready to pack the notebooks for their journey home where they would be received by Doris Hamburg of the Library's Conservation Division.

On Sotheby's side, because David Redden and Selby Kiffer were away for the day, a staffer took charge of us. She placed us in the elegant Founder's room, furnished with two library tables, for one hour, where we had to work rapidly. Sotheby's had drawn up a draft receipt using their improvised descriptors. I verified the identity of each item by (1) matching selected photostat pages made from the notebooks before they were removed from the Library with the originals, (2) assigning the appropriate L.C. (1955) catalog numbers, (3) adding item numbers from the 1954 publication, and (4) counting notebooks leaves. Terry Wallis rechecked counts, which differed slightly from Sotheby's, and we corrected their record. As I certified each item, an agent photographed it, and the conservator created custom-made travel housings with foam backings and then locked the notebooks into a hard suitcase. As guests were arriving for a noon luncheon, agent Gibbons took custody of the suitcase, and we departed.

The New York agents drove us to Pennsylvania Station in a mysteriously ragged car and then sped away. We three just had time for lunch inside the station, during which hour the suitcase occupied the fourth chair at table. On the train, one of us had contact with the suitcase at all times.

I spent one of those four hours with the conservator discussing the condition of the notebooks and likely preservation measures. The thin cardboard butterfly was in fairly good condition, its colors bright, and its fine wire still attached, though apparently smaller than in our photograph. The opening of the butterfly had a limitation which would make it inadvisable to flatten it out. A few of the problems with the notebooks, seen on quick review, were: torn leaves, badly faded pages in one small, fragile notebook, limited opening capability of one, and loose 
leaves - very likely out of order-in another. There were several pages which had been cut out near the binding. Upon examination, it seemed clear that Whitman had done this in converting the book (the " 1847 " one) from an earlier use as a ledger. It was his habit to fashion notebooks out of volumes originally intended for other purposes. We discussed the need to microfilm the notebooks for service in the Manuscript Reading Room (the rest of the Harned collection is already served as microfilm only), and we decided there should be two positive microfilms available so that the originals, because of their condition, would not need to be served even if a microfilm was on loan.

I spent most of the time talking with Special Agent Gibbons, who luckily is a Whitman enthusiast. He enjoys claiming lost government arts properties and had recently returned a valuable painting to the Smithsonian. He wanted to pursue the other six missing notebooks, and we discussed the three main avenues I saw for investigation. I have met with him several times since, and there is still some hope of retrieving the remaining notebooks. [See illustrations following this essay.]

When we arrived at the Library of Congress Madison Building, I carried the suitcase so that the guard would not have to open it. I told the officer that an "agent" was with me. Agent Gibbons displayed his identification. The guard asked if he "was carrying," and he replied affirmatively: he was indeed armed. The guard momentarily disabled the entrance metal detector, and we arrived in Conservation at 5:45, where the last member of the team, Doris Hamburg, waited. The F.B.I.required paperwork for the transfer took another half hour. Gibbons had to rewrite the Sotheby's receipt on an F.B.I. form showing that he transferred custody to the Library. I added identifying catalog numbers and signed on behalf of the Library. Ms. Hamburg signed as witness.

At this point, the agent took a quick tour of the Conservation lab, and a Library manager arrived to see the notebooks, about which a great deal of excitement had been generated. She was already planning to have the returned materials electronically scanned. They would also be photographed for the forthcoming article in Civilization as well as for the Library's Gazette. The preservation report would be needed so that appropriate measures could be taken during the scanning process to prevent further stress on these artifacts, which had been away from professional care for fifty years.

Ms. Hamburg then removed the notebooks, still in their foam housings, from the case Ms. Wallis had unlocked, placed them in a flat archival box, and secured them in the safe. At 6:15 I showed Agent Gibbons out of the Library. Since he could not find a cab, I drove him to agency headquarters in the rather sinister area of Buzzard's Point. I returned home at 7:00 p.m., after the most remarkable workday of my twenty-two-year career at the Library of Congress. 


\section{The Foreground}

The notebooks, together with the cardboard butterfly photographed on Whitman's finger in the $1800 \mathrm{~s}$, had spent approximately 30 years in custody of the lawyer's father, who reportedly received them as a gift from a friend. The identity of that friend is known but remains confidential for the F.B.I.'s on-going investigation in regard to the six notebooks still missing from the Harned/Whitman collection (which contains some 3,000 items).

The returned five items were part of a group of twenty-four Whitman notebooks deposited with the Library in 1918 by Thomas B. Harned of Philadelphia, one of Whitman's three literary executors, and converted to a gift in 1919. Harned, a Philadelphia lawyer, first offered his collection to Librarian of Congress Herbert Putnam in 1917, noting that he was also considering New York Public Library, but that he had a "decided preference" for Washington, where Whitman had lived "for an important ten years of his life." He wanted all Whitman manuscripts to accumulate in the Library of Congress. In a September 7, 1917, letter Harned said he would hold back Whitman's notebooks ("the most important of all") and some letters from his share of the papers until after fall publication of two or three books based on those materials. A hand-written memo dated November 15, 1918, noted that the Manuscript Division received "this afternoon" twenty-four notebooks "and a lot of miscellaneous sheets, in yellow covers," which were later counted as a twenty-fifth notebook. Access to the notebooks was restricted until after Holloway's two-volume work appeared in 1921. All restrictions fell away in 1925, after Harned's death, and scholars extensively consulted the notebooks until 1942.

During the days following the December 7, 1941, attack on Pearl Harbor, the Library's Keeper of the Collections Alvin W. Kremer and his staff crated up thousands of treasures from the collections, including Whitman papers from the Harned collection, for evacuation early in 1942. Four of the Library's wartime repositories were Denison University in Granville, Ohio, the Virginia Military Institute and Washington and Lee University in Lexington, and the University of Virginia in Charlottesville. The last shipment of 4,789 packing cases-the equivalent of twenty-six freight car loads-of materials was returned to the Library on Tuesday, September 26, 1944.

The small container that supposedly held the twenty-four Whitman notebooks and the butterfly still was sealed upon its return in 1944 . When it was opened, however, there were only 14 notebooks and no butterfly. This aspect of the mystery-how and when the ten notebooks were removed-may never be solved, in spite of thorough investigations. 
The Library conducted a meticulous internal search and external call for the notebooks for the next ten years. Some information gathered in that investigation, as well as clues from the 1995 F.B.I. investigation, remains confidential in the hope that it may lead to the retrieval of the other six missing notebooks.

The contents of the recovered notebooks are by no means entirely new to literary students. Before their disappearance, the notebooks were partially published in editions and scholarly works by Emory Holloway (1921), Clifton Joseph Furness (1928), and Charles I. Glicksberg (1933). It would take a line-by-line comparison of the notebooks with the variously published portions to determine precisely what is "new." In general, however, Holloway tended to omit sections of apparently little interest to him, such as lists of names and addresses, and he did not record any of Whitman's deletions or discarded word choices. Furness and Glicksberg each published only portions relevant to their own themes; all three often provided their own titles, though Holloway remained the standard. In all of the publications, including the 1954 Library of Congress pamphlet, for which compilers made up titles based on known highlights, the most reliable documents are the partial photographs of a few original pages.

In 1984, Edward Grier published his meticulous six volume edition, Walt Whitman: Notebooks and Unpublished Prose Manuscripts (New York University Press), complete with detailed physical descriptions of the notebooks and notation of each known Whitman deletion. In regard to the returned Harned/Whitman notebooks, however, Grier is difficult to use because (1) he reconstructs from scattered information; (2) he uses a "subject" arrangement for the notebooks, when they are almost always comprised of a wide range of thoughts on many topics; (3) when reconstructing from fragments, he creates an item's internal order so that the text makes most sense, whereas the original may be discontinuous; and (4) he uses the incipit form of titling, which only works if the very first words of a notebook are actually known. Thus it is difficult even to locate the four notebooks in Grier's volumes, but they are: "Albot Wilson" on pp. 53-83 of Volume I (missing notebook number 1; LC Catalog number 80); "You Know How the One" on pp. 124-127 of Volume I (missing notebook number 2; LC Catalog number 86); "Return My Book" on pp. 478-524 of Volume II (missing notebook number 5; LC Catalog number 94); and "Scene in the Woods" on pp. 651652 in Volume II (missing notebook number 7; LC Catalog number 101). 


\section{Highlights}

Grier turns out to be fairly accurate about the first words of the notebooks. For LC \#80, however, the original shows a faint " $T$ " before "albot," confirming his footnote referring to Talbot Wilson. For LC \#94 the beginning may read, "Return this book," but since "Walter Whitman" is written over this, it is difficult to be sure. The order of passages in LC \#86 is radically different from the way Grier printed them, and he did not have photostats of at least one brief passage: "consecration of priests in Trinity Church-interlinking of hands." I have not compared Grier's text for LC \#94 with the very lengthy original, largely because of his decision to rearrange it "chronologically." For LC \#101 Grier omits the "At Antietam" passage describing a barn full of wounded soldiers, though Glicksberg printed it.

Not only are the Harned collection notebooks among the first Whitman papers received by the Library of Congress, whose premier collection of Whitman materials has grown to more than 98,000 items, largely due to the acquisition of the Charles E. Feinberg/Whitman collections, but they contain early versions of the poems that appeared in Leaves of Grass. These notebooks are the primary record of the poet's very early career, while he was a journalist and during his years in Washington when he served as a volunteer hospital worker during the Civil War.

The "most important" of the four recovered notebooks was so labelled, apparently by Harned, because of an internal date of 1847 remaining on an old account book page, the bottom of which was usedprobably at a much later date-for early drafts of poetry. Pages we have numbered as 3-16 remain only as stubs (apparently cut out by Whitman). When we retrieved the book, a group of leaves was loose and had been inserted in the wrong place in the book; the conservator studied the book's structure, stains, etc., and rebound these in the proper place. This notebook now contains 47 small leaves densely written in pencil with aphorisms, observations, and extensively revised poetry, including early drafts of "Song of Myself." A more likely date for these draftswith prose breaking into poetry-is 1853-1854.

The other three notebooks, also written largely in pencil, include thoughts on perception and the human senses, names and addresses of friends and acquaintances, and drafts of Civil War poetry. One includes notes about wounded soldiers Whitman was nursing in 1862: "bed 15wants an orange ... bed 59 wants some liquorice . . 27 wants some figs and a book." Looking at the notebooks Whitman kept while he made his rounds of Civil War hospitals in Washington, one can imagine the poet bending over the bed of one wounded man to hear his whisper, then fishing for his notebook and a stub of pencil to write: " 20 years of age / down with pneumonia/talks in a whisper/has been sick two months-one month here. 7 have died since he has been here / is pretty 
weak now from lying so much in bed / would like some oranges. . .." On another page, he noted "The Comic Side of Death," and described a brave man's last night, telling his nurse: "Give me another chew of tobacco," and "Give me some more toddy." In another book, Whitman pencilled: "You know now the one brain includes those beautiful wonders and converging ["wonders and converging" lined out] perceptions or senses the subtle processes of thought and reason and causality. . . ."

The frontispiece of the birthday edition of Leaves of Grass, May 31, 1889 , portrayed Whitman, with long gray beard and broad-brimmed hat, seated with a butterfly on an outstretched finger. Scholars concluded that the butterfly in the photo was in fact the cardboard model found among Whitman's papers after his death in 1892. Ever the selfpromoter, Whitman liked to convey an image of himself as one-withnature. Esther Shepherd, an early scholar who used the Harned collection, described finding the butterfly in one of the notebooks (Walt Whitman's Pose [New York: Harcourt Brace, 1938], 250-252). She furnished descriptions and photographs of the butterfly for the Library's original investigation, so that the verse printed on the butterfly has long been known:

The First Begotten

of the Dead

For Us He Rose, Our

Glorious Head,

Immortal Life

To Bring.
What Though the Saints

Like Him Shall Die,

They Share Their

Leader's victory,

And Triumph with

Their King

- Fohn Mason Neale

Only after seeing the real object, however, did I learn that one word was invisible in our best photograph. Down the middle of the artifact is printed the word, "EASTER." The fine wire which once wrapped around Whitman's generous finger had somewhere along the journey of the last half century been shortened so that the loop no longer fit an adult hand. Esther Shepherd found the butterfly inserted in one of the Harned notebooks. The photostat in her book showed the butterfly resting on a manuscript page which was assumed lost along with the butterfly in 1942, but in 1954 curators located it inserted in Notebook \#113 (Camden, ca. 1880); in Whitman's hand, it read: "(this means far more than appears at first)."

\section{Surrogates}

Since their return home to the Library of Congress, I have had very little time with the original notebooks, which have been kept under the tightest security. After assessing the condition of the returned materials 
and plotting a course for their preservation, the Library decided to make surrogate copies for researchers. The Conservation Office jumped at the opportunity to make the notebooks an integral part of the new National Digital Library program. Ann Seibert, senior paper conservator, took charge of the scanning project - the first the Library had performed on such fragile and difficult materials. With painstaking care, the preservation staff created remarkably clear digital images of the poet's jottings and scribblings in the four fragile notebooks. Both the top and bottom of the delicate cardboard butterfly were scanned into the digitized system. In order to avoid further damage to the paper, the two larger notebooks had to be disbound for the scanning. The subsequent restoration would be worthwhile because the fidelity of the archivally scanned images, now available on the Internet [via World Wide Web connection: "http://LCWEB.LOC.GOV"] will make it virtually unnecessary to consult the originals. The digital version of the notebooks is at this writing under contract for conversion to microfilm for public reference and is expected to be available by autumn of 1995 . It will be available in the Manuscript Reading Room of the Library of Congress, and a copy will be available for authorized interlibrary loan.

The digital versions of the Whitman images include a Home Page, selection menus, and explanatory texts. Researchers are guided to screen images of notebook pages, color images of the cardboard butterfly, and a description of how the notebooks were conserved. Scholars appear to love the digital format. In some cases it actually improves the image, and users can click on a detail and enlarge it on-screen for closer examination (e.g., the word EASTER on the butterfly's spine only comes into view by using the zoom feature).

The Rare Book Conservator has designated the original notebooks to a "Handle Only Once" category. She prepared detailed description and condition reports for each of the four notebooks and the butterfly and prescribed conservation treatment for each. For example, for the " 1847 " notebook, she proposed these steps: (1) document photographically; (2) disbind by separating text block pages, leaving the cover intact; (3) treat paper-remove residual spine adhesive, mend and reinforce spine folds with Japanese paper and wheat starch paste, determine $\mathrm{pH}$ of paper, and deacidify if necessary; (4) consolidate and reinforce original spine to flex independently of text block; (5) resew text block and reinsert in original case; (6) house with other notebooks in a double tray box.

Of course, the textual information is not the only valuable aspect of such materials. The objects convey information for cultural historians who can learn something about the history of papers and printing and about Whitman's habits by examining the papers he cut and bound to make two of the notebooks. The artifact connects us to the maker. 
Mended, strengthened, deacidified, rebound exactly as the poet left them, and returned to the Library's archives - the world's largest repository of Whitman materials - these notebooks, if access to them is kept to a minimum, will repose in acid-free boxes for centuries to come.

Manuscript Division, Library of Congress

Four of the ten missing Whitman notebooks have now been returned to the Library of Congress. The Library and the FBI are still actively seeking the return of the six notebooks that remain missing. On the following pages are reproductions of sample pages from each of the still-missing notebooks. Anyone who has information about any of these notebooks should contact Alice Birney, Manuscript Division, Library of Congress, 112 Fifth Avenue NE, Washington, D.C. 20002. 


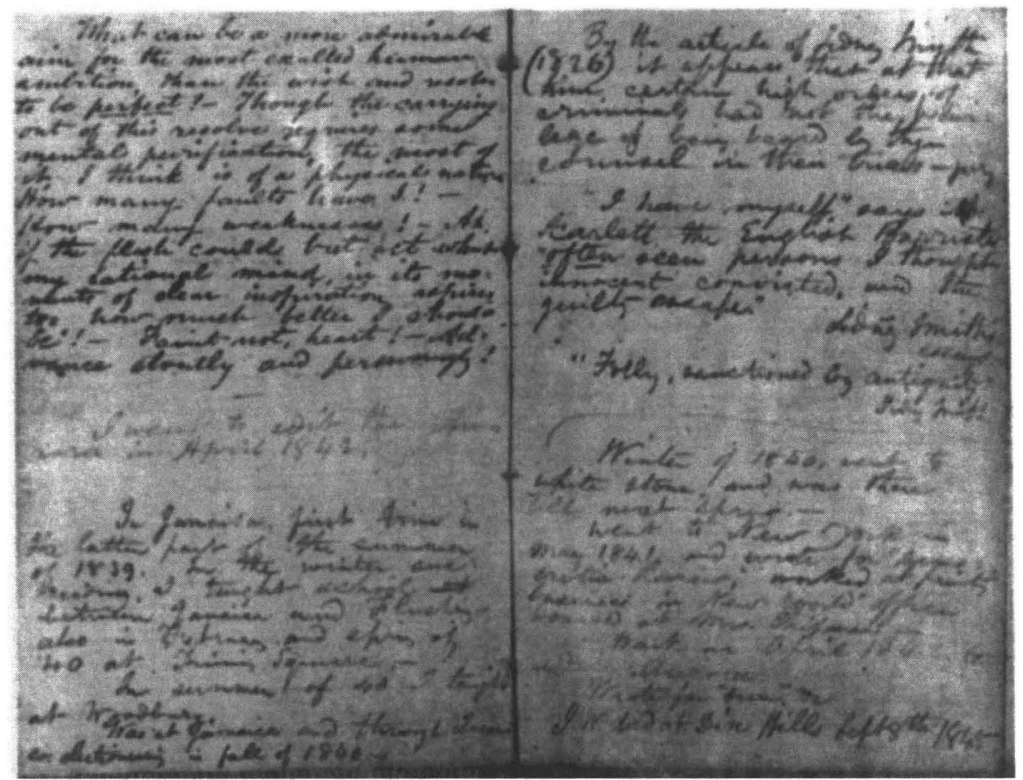

1. "Fugitive Slave Law" Notebook (leather-backed notebook containing references to Fugitive Slave Law).

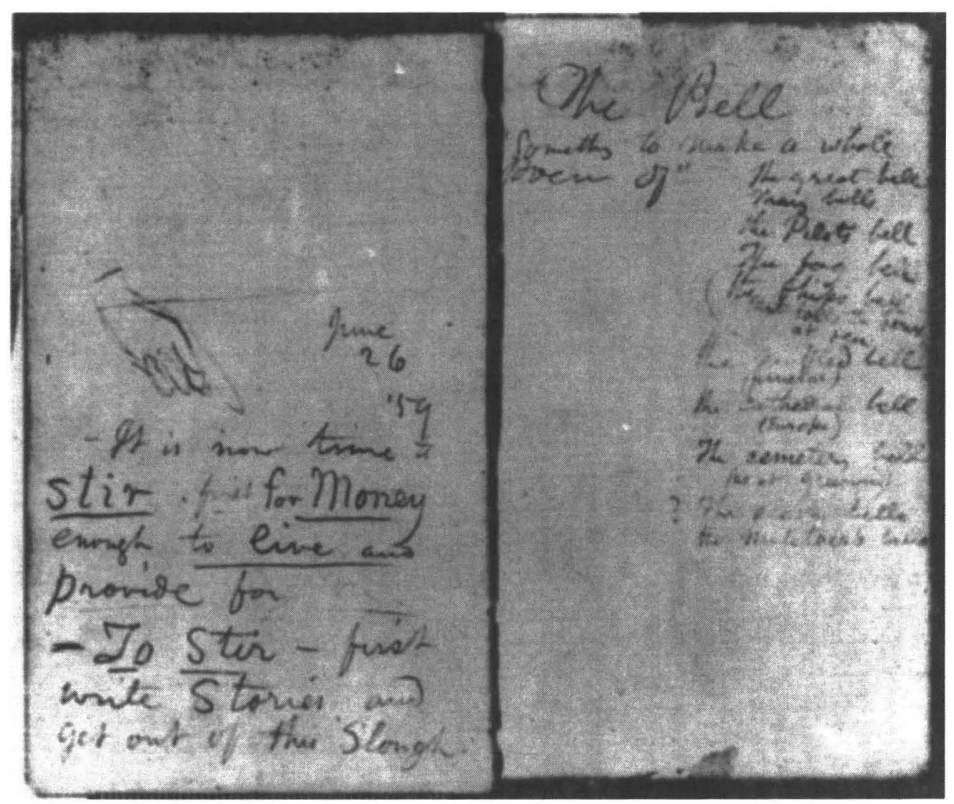

2. "Tintype" Notebook (old leatherbound notebook in which Whitman had mounted a tintype of an unidentified young woman). 


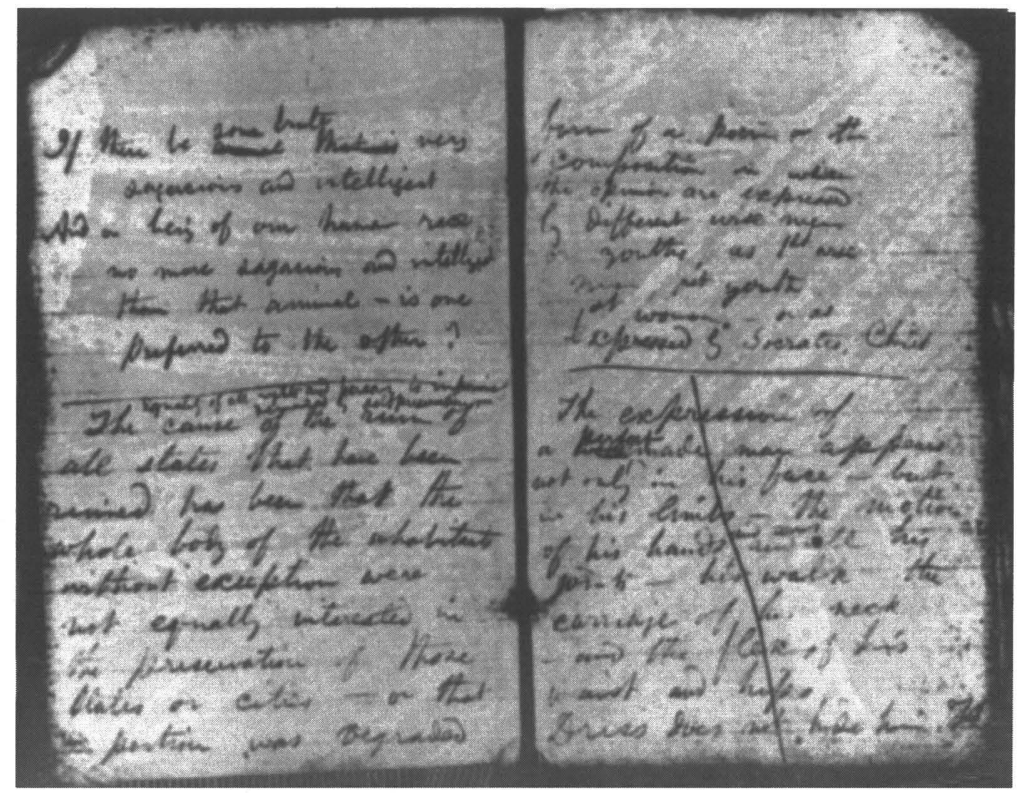

3. "American Opera" Notebook (belonging to period before 1855).

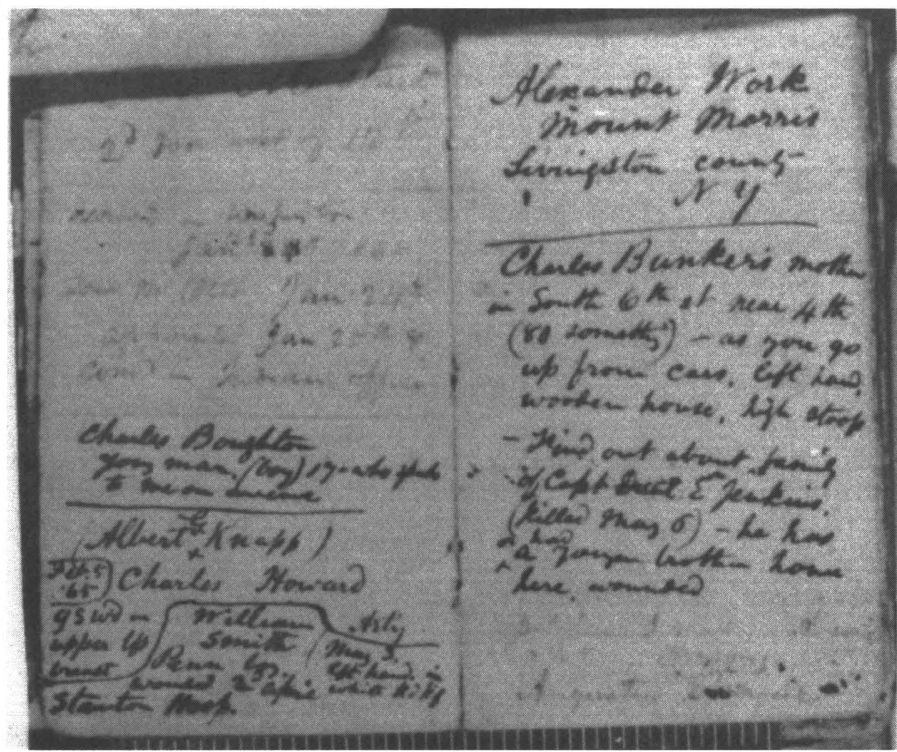

4. "Hospital" Notebook No. 3, 1865 (one of the notebooks used by Whitman in his Civil War hospital work). 


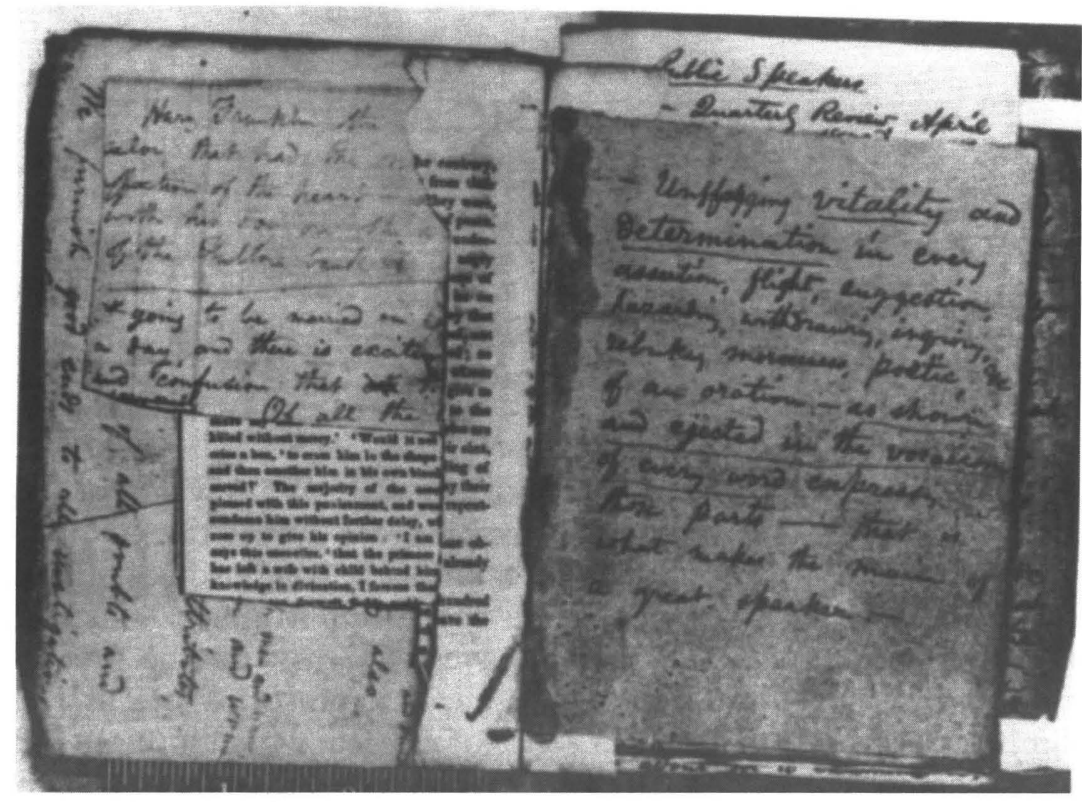

5. "Oratory" Note and Scrapbook (most of contents consist of printed clippings, often annotated and underlined by Whitman).

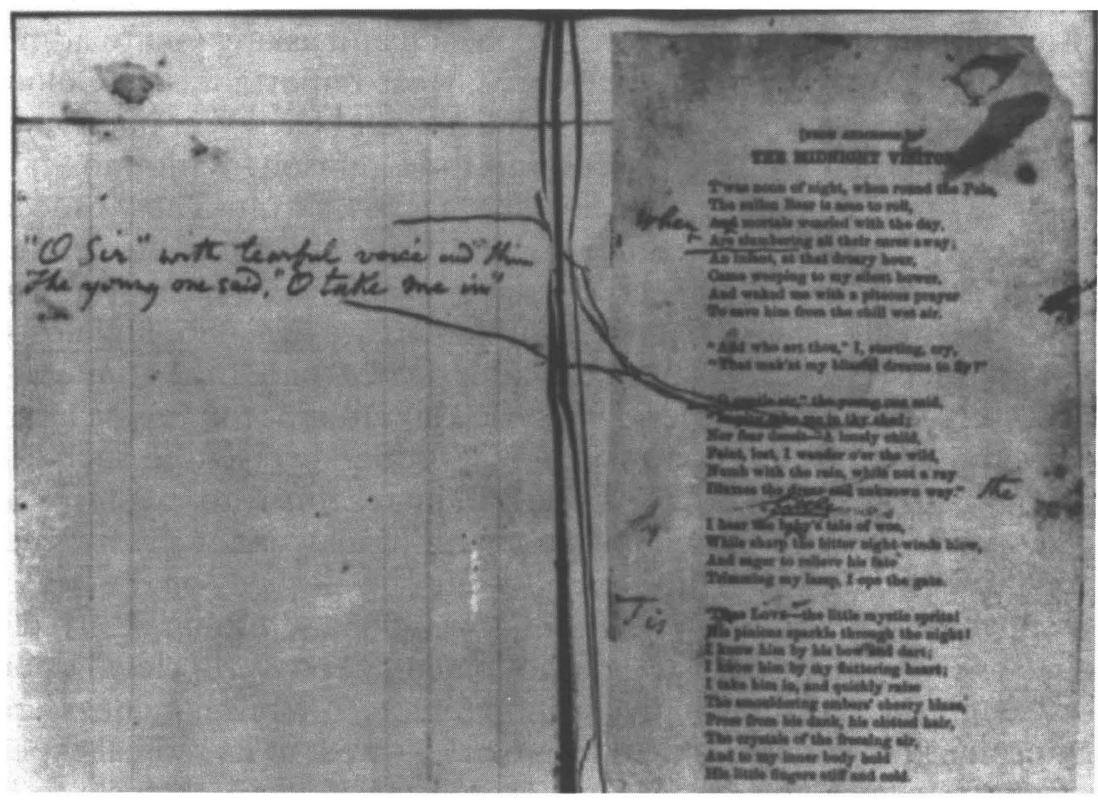

6. The "Reading Book" (contains galley sheets of poems by Whitman and others, used by Whitman for his public readings). 